\title{
PROCESSO DE ESTABILIZAÇÃO DE RESÍDUOS ORGÂNICOS: VERMICOMPOSTAGEM VERSUS COMPOSTAGEM
}

\author{
Paulo R. Dores-Silva, Maria Diva Landgraf e Maria Olímpia de O. Rezende* \\ Instituto de Química de São Carlos, Universidade de São Paulo, CP 780, 13560-970 São Carlos - SP, Brasil
}

Recebido em 14/6/12; aceito em 20/11/12; publicado na web em 6/3/13

\begin{abstract}
THE ORGANIC WASTE STABILIZATION PROCESS: COMPOSTING VERSUS VERMICOMPOSTING. Two processes are used to stabilize organic wastes: composting and vermicomposting. There are no studies in the literature showing which process is most effective over the short term. In this study, 3 organic wastes were composted and vermicomposted for 90 days, and the parameters $\mathrm{pH}$, effective cation exchange capacity, total organic carbon, total Kjeldahl nitrogen, $\mathrm{P}_{\text {total }}, \mathrm{E}_{4} / \mathrm{E}_{6}$ ratio, hydrophobicity and aromaticity indexes were determined. In all experiments, vermicomposted materials showed higher stability, proving a superior tool for stabilization of these organic wastes.
\end{abstract}

Keywords: compost; vermicompost; organic wastes.

\section{INTRODUÇÃO}

A disposição inadequada de resíduos orgânicos produzidos por atividades agrícolas pode gerar graves impactos ao meio ambiente como, por exemplo, a eutrofização dos corpos d'água; desta forma, torna-se importante a disposição desses resíduos de maneira ambientalmente adequada. Nesse contexto a disposição agrícola consiste em um processo economicamente viável e sustentável, auxiliando no sequestro de carbono pelo solo e sendo um meio de aliviar o aumento de $\mathrm{CO}_{2}$ na atmosfera, que tem como possíveis fontes a queima de combustíveis fósseis e as práticas agrícolas. Sendo assim, a disposição adequada de resíduos orgânicos pode devolver ao solo parte do carbono que lhe foi tirado. ${ }^{1-3}$

A incorporação de matéria orgânica (MO) a solos agricultáveis, proveniente de resíduos gerados no próprio empreendimento, diminui o input de $\mathrm{CO}_{2}$ na atmosfera, além de auxiliar na retenção de umidade, melhorar a textura dos solos, dificultando assim o processo de erosão e fornecendo macro e micronutrientes às plantas. No entanto, a MO contida naqueles resíduos deve ser devolvida ao solo com certo nível de estabilização, com macro e micronutrientes em uma forma mais assimilável pelas plantas e microrganismos presentes no solo, para tanto algum processo químico, físico ou biológico deve ser utilizado. ${ }^{4-6}$

Dois processos para a estabilização de materiais orgânicos, que visam sua posterior disposição agrícola, são mundialmente conhecidos e utilizados: a compostagem, realizada exclusivamente por microrganismos, e a vermicompostagem, realizada por uma simbiose entre minhocas e microrganismos que vivem em seu trato digestivo. ${ }^{7,8}$

A compostagem é o processo de transformação biológica de materiais orgânicos, tais como palha de arroz, café, papel etc., em fertilizantes orgânicos utilizáveis na agricultura. Este processo envolve transformações de natureza bioquímica, promovidas por milhões de microrganismos presentes no próprio material ou que nele são adicionados por meio de um pré-inóculo, que utilizam a matéria orgânica in natura como fonte de energia, nutrientes minerais e carbono, promovendo a mineralização de parte do material e a humificação de outra parte. ${ }^{9}$

O processo de humificação pode ser entendido como o inverso do processo de mineralização. Enquanto o processo de mineralização

\footnotetext{
*e-mail: mrezende@iqsc.usp.br
}

faz com que o material inicial se transforme em $\mathrm{CO}_{2}, \mathrm{H}_{2} \mathrm{O}$ e sais inorgânicos, o processo de humificação representa a conversão da matéria orgânica recente em húmus, composto rico em materiais orgânicos de alto peso molecular, como ácidos fúlvicos, ácidos húmicos e humina que são as frações da matéria orgânica com alto grau de estabilização. ${ }^{10}$

Propõe-se neste estudo avaliar o comportamento das matrizes compostadas e vermicompostadas, com o intuito de identificar as diferenças entre composto e vermicomposto, apontando qual dos dois processos é mais eficaz na estabilização de resíduos orgânicos em um curto intervalo de tempo, com vistas à incorporação de MO a solos agricultáveis, proveniente de resíduos gerados no próprio campo, diminuindo, assim, o input de $\mathrm{CO}_{2}$ na atmosfera.

\section{PARTE EXPERIMENTAL}

\section{Montagem dos experimentos}

Todos os experimentos foram realizados no rancho Santa Isabel, no município de São Carlos, SP. Para produção dos vermicompostos foram utilizadas caixas de compensado, não herméticas e dispostas em local fechado para cada experimento: palha de arroz + esterco bovino (PA), bagaço de cana-de-açúcar + esterco bovino (BC) e resíduos vegetais de hidroponia + esterco bovino (RV). Todas as misturas tiveram a proporção de 1:1 v/v, sendo que as misturas foram realizadas após lavagem do esterco com água, para retirada de ureia. ${ }^{11,12}$ As caixas possuíam dimensões de 0,70 m de largura, 0,70 $\mathrm{m}$ de comprimento e $0,70 \mathrm{~m}$ de altura cada. Após a devida homogeneização dos materiais, esses foram acondicionados nas caixas, mantendo-se a umidade entre 40 a $60 \%$ e a temperatura entre 20 e $30{ }^{\circ} \mathrm{C}$. Todos os experimentos tiveram 5 replicatas, totalizando um total de 15 caixas. A inoculação da espécie Eisenia foetida foi feita com a aplicação de 1000 minhocas por $\mathrm{m}^{3}$.

A vermicompostagem teve lugar em caixas, para assim se adequar melhor às necessidades das pequenas propriedades características de agricultura familiar, com vistas a reciclar os resíduos gerados no campo e utilizá-los nas próprias hortas e jardins, e também para evitar a fuga das minhocas. Já os compostos foram produzidos em leiras, com dimensões de aproximadamente $1,5 \mathrm{~m}$ de altura e $2 \mathrm{~m}$ de largura em local fechado e sobre uma lona para evitar a lixiviação de nutrientes e outros materiais. Optou-se por leiras para a 
produção dos compostos primeiramente por se tratar do modo mais comum de se realizar esse processo e, secundariamente, devido à maior reprodução microbiana neste tipo de estruturação, uma vez que o boom microbiano seria muito diminuído se a compostagem fosse realizada em caixas iguais às da vermicompostagem; a ideia foi avaliar qual processo é mais eficiente reproduzindo o mais fielmente possível a maneira "padrão", por assim dizer, de realização de cada processo. As matérias-primas foram as mesmas utilizadas para a vermicompostagem, possuindo as mesmas proporções inicias de resíduos e com umidade mantida entre 40 a $60 \%$, o controle da etapa termofílica foi realizado com o material sendo revolvido frequentemente durante os 90 dias de compostagem. A primeira coleta foi realizada após a homogeneização cuidadosa das misturas, sendo coletada uma alíquota de $10 \mathrm{~kg}$ de cada mistura.

Decorrido um intervalo de 90 dias após o início do estudo, ${ }^{12,13}$ foi realizada a coleta do composto e vermicomposto; após cautelosa homogeneização de cada caixa e cada leira, foi retirada uma alíquota de $2 \mathrm{~kg}$ de cada caixa, totalizando 5 amostras individuais para análise de cada mistura vermicompostada e 5 alíquotas de $2 \mathrm{~kg}$ de cada leira, totalizando 5 amostras para análise da mistura compostada. Todas as análises foram realizadas no material inicial, compostado por 90 dias e vermicompostado por 90 dias, para posterior comparação das transformações causadas nas matrizes iniciais após compostagem e vermicompostagem.

Foram avaliados os seguintes parâmetros: $\mathrm{pH}$, teor de matéria orgânica, capacidade de troca catiônica efetiva (CTCef), carbono orgânico total (COT), nitrogênio Kjeldahl total (NKT), $\mathrm{P}_{\text {total }}$ (fósforo total), razão $\mathrm{C} / \mathrm{N}$ e razão $\mathrm{CTCef/COT}$, índices de hidrofobicidade e aromaticidade por meio de espectros na região do infravermelho e razão $E_{4} / E_{6}$ por meio de espectroscopia no UV-Vis. O composto bem como as amostras iniciais foi submetido às mesmas análises.

\section{Metodologia}

O teor de MO foi calculado por aquecimento da amostra, em mufla, à temperatura de $550{ }^{\circ} \mathrm{C}$, e determinação por gravimetria. ${ }^{14}$

$\mathrm{O} \mathrm{pH}$ foi determinado com cerca de 5,0 $\mathrm{g}$ de amostra adicionada a $50 \mathrm{~mL}$ de $\mathrm{CaCl}_{2} 0,01 \mathrm{~mol} \mathrm{~L}^{-1}$. A determinação dos cátions metálicos totais trocáveis $(\mathrm{S})$ foi efetuada em uma amostra seca de aproximadamente 2,50 g adicionada a $25 \mathrm{~mL}_{\text {de }} \mathrm{CH}_{3} \mathrm{COOH} 1,0 \mathrm{~mol} \mathrm{~L}^{-1}$. A mistura foi levada à agitação orbital constante durante $1 \mathrm{~h}$. Decorrido esse tempo, mediu-se o pH da suspensão; essa determinação baseia-se no deslocamento dos cátions metálicos trocáveis dos componentes da amostra pelo próton do $\mathrm{CH}_{3} \mathrm{COOH}$. Os cátions trocáveis correspondem à soma dos íons $\mathrm{Ca}^{2+}, \mathrm{Mg}^{2+}, \mathrm{K}^{+} \mathrm{e} \mathrm{Na}^{+}{ }^{15-17}$

A acidez trocável (AT) corresponde aos teores de $\mathrm{H}^{+}$e $\mathrm{Al}^{3+}$ liberados pela reação com solução não tamponada de $\mathrm{KCl} \cdot{ }^{18}$ Para tanto, misturaram-se 5,00 g das amostras com 50,00 mL de $\mathrm{KCl} 1,0$ mol L $\mathrm{L}^{-1}$ e, após agitação, seguida de repouso, filtrou-se a suspensão e titulou-se com $\mathrm{NaOH} 0,05 \mathrm{~mol} \mathrm{~L}^{-1}$, utilizando-se como indicador fenolftaleína, determinando-se assim a acidez trocável.

As determinações do teor de carbono orgânico foram feitas em um aparelho TOC-V COH Shimadzu, acoplado ao módulo para amostras sólidas SSM-5000A Shimadzu. Para cada determinação foram pesados $100,00 \mathrm{mg}$ de amostra seca e triturada.

A determinação de nitrogênio e de fósforo foi conduzida via espectrofotômetro Hach pelo método 399 nitrogênio total Kjeldahl (NKT) e 480 para o $\mathrm{P}_{\text {total. }}{ }^{18}$

A razão atômica $\mathrm{C} / \mathrm{N}$ foi obtida pela divisão dos resultados em porcentagem mássica obtidos para o carbono orgânico total e o nitrogênio Kjeldahl total.

A razão CTCef/COT foi obtida pela divisão numérica entre os valores encontrados para capacidade de troca catiônica (CTCef), em $\mathrm{mmol}_{\mathrm{c}} \mathrm{kg}^{-1}$, e o carbono orgânico total, em porcentagem mássica, ambos referidos à amostra em base seca.

Os espectros na região do infravermelho das amostras foram obtidos em um espectrofotômetro com transformada de Fourier da marca Bomem MB-102. Pesou-se, em uma balança com precisão de $0,01 \mathrm{mg}$, aproximadamente 0,50 mg de amostra, e, após adicionar $150,0 \mathrm{mg}$ de $\mathrm{KBr}$, a mistura foi pulverizada e prensada, formando uma pastilha, que foi então analisada no espectrofotômetro. Efetuaram-se, para cada análise, 32 varreduras de 4000 a $400 \mathrm{~cm}^{-1}$, com resolução de $4 \mathrm{~cm}^{-1}$. Foram realizadas 5 análises para cada amostra. Os espectros foram tratados pelo programa Win-Bomem Easy 3.04, acertando-se a linha de base por múltiplos pontos (Multiple point level) nos valores de número de onda iguais a 3680, 2680, 2220, 1810 e $860 \mathrm{~cm}^{-1}$, e atenuando-se o sinal (smoothing) pelo modo Fourier a $45 \%$.

Os espectros de absorção na região do UV-Vis foram obtidos da seguinte maneira: dissolveram-se cerca de 5,0 mg de material seco e macerado em $50,0 \mathrm{~mL}$ de uma solução de bicarbonato de sódio $\left(\mathrm{NaHCO}_{3}\right)$ 0,025 mol L-1, com pH 8,4. As medidas de absorbância da solução foram obtidas a partir do espectro na região do visível, utilizando um espectrofotômetro de UV-Visível Hitachi U3501 e uma cubeta de quartzo de $1 \mathrm{~cm}$ de caminho óptico.

Com os valores de absorbância nos comprimentos de onda 465 e $665 \mathrm{~nm}$, calculou-se a razão $E_{4} / E_{6}$.

Para o tratamento matemático dos dados obtidos admitiu-se uma estatística paramétrica. As determinações foram feitas em quintuplicata para cada experimento, totalizando 25 repetições para cada mistura, tanto para as compostadas quanto para as vermicompostadas, sendo, então, calculada a média dos valores e o erro para um intervalo de confiança de $95 \%$ calculado pela Equação 1:

$$
\mathrm{e}= \pm(\mathrm{tx} \sigma) / \sqrt{ } \mathrm{n}
$$

sendo: $\mathrm{e}=$ erro $; \mathrm{t}=$ coeficiente de Student tabelado; $\sigma=$ desvio-padrão e $n=25$

\section{RESULTADOS E DISCUSSÃO}

\section{Teor de matéria orgânica e carbono orgânico total}

Os processos de estabilização da $\mathrm{MO}$ recente levam à mineralização de parte do material lábil e à humificação de outra parcela, logo, existe uma diminuição no teor de matéria orgânica após os processos de estabilização, uma vez que parte do carbono contido no material inicial evolui para a atmosfera na forma de $\mathrm{CO}_{2}$, devido à respiração dos organismos que transformam o material.

A Figura 1 apresenta a variação nos teores de MO e COT iniciais de cada mistura e após passarem pelo processo de compostagem e vermicompostagem.

Como esperado, houve uma diminuição no teor de MO dos experimentos PAC (Palha de Arroz + Esterco Bovino Compostados), PAV (Palha de Arroz + Esterco Bovino Vermicompostados); BCC (Bagaço de Cana + Esterco Bovino Compostado), BCV (BCV Bagaço de Cana + Esterco Bovino Vermicompostados) e RVC (Resíduo Vegetal + Esterco Bovino Compostados) e RVV (Resíduo Vegetal + Esterco Bovino Vermicompostados) quando comparados com as matrizes de origem, sendo que os vermicompostos (PAV, BCV e RVV) apresentaram uma menor porcentagem em massa de MO, quando comparados com os compostados (PAC, BCC e RVC) (Figura 1a). Isso ocorre, pois além do processo de degradação microbiológica existe o processo de alimentação das minhocas, que utilizam parte da MO existente na matriz para seu desenvolvimento, e que, além da incorporação do carbono orgânico promovida pelas minhocas, 
existe a contribuição do processo inverso, ou seja, de mineralização do carbono orgânico para $\mathrm{CO}_{2}$.

Analisando a Figura 1b nota-se que o COT diminuiu após os processos de compostagem e vermicompostagem, isso para todas as matrizes estudadas. Observa-se, também, que o processo de vermicompostagem se mostra mais eficiente na remoção do COT, quando comparado com o processo de compostagem. O COT apresenta uma
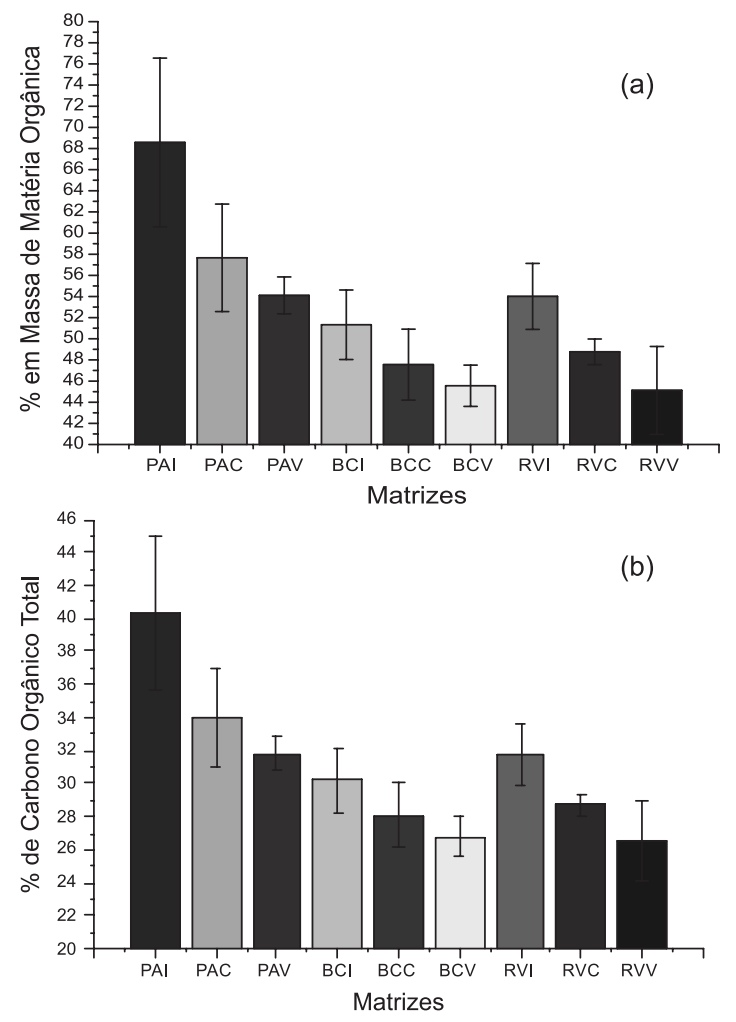

Figura 1. Variação da MO (a) e do COT (b) nas matrizes estudadas: PAI (palha de arroz + esterco bovino inicial), PAC (palha de arroz + esterco bovino compostados), PAV (palha de arroz + esterco bovino vermicompostados); BCI (bagaço de cana + esterco bovino inicial), BCC (bagaço de cana + esterco bovino compostados), BCV (bagaço de cana + esterco bovino vermicompostados); RVI (resíduo vegetal + esterco bovino inicial), $R V C$ (resíduo vegetal + esterco bovino compostados), $R V V$ (resíduo vegetal + esterco bovino vermicompostados) diminuição mais acentuada no vermicomposto devido às mesmas razões que corroboram para a diminuição do teor de MO.

\section{Capacidade de troca catiônica e acidez das amostras}

Entende-se por CTC efetiva (CTCef) a capacidade de troca de cátions ou a capacidade em reter cátions próximo ao valor de seu $\mathrm{pH}$ natural, sendo calculada como a soma dos cátions metálicos totais $(\mathrm{S})$, referentes às bases $\mathrm{Na}^{+}, \mathrm{K}^{+}, \mathrm{Ca}^{+2} \mathrm{e} \mathrm{Mg}^{+2} \mathrm{e}, \mathrm{H}^{+}+\mathrm{Al}^{+3}$ referentes à acidez trocável (AT). Quando se trata de compostos orgânicos variações no $\mathrm{pH}$ podem influenciar diretamente na capacidade de retenção de cátions, uma vez que o desprotonamento de grupos funcionais como grupos carboxílicos e fenólicos pode gerar cargas negativas altamente estabilizadas por ressonância, que contribuem para o aumento da CTCef; da mesma maneira, a presença de $\mathrm{H}^{+}$no meio advinda da degradação dos compostos orgânicos pode gerar a protonação desses grupos diminuindo, assim, os sítios ativos para a adsorção das bases e posterior troca. Daí a importância de se analisar em conjunto as variações na CTCef e no $\mathrm{pH}$, antes e após os dois processos.

Na Tabela 1 apresentam-se os resultados do valor S, AT, CTCef, que corresponde à somatória da acidez total com o valor $\mathrm{S}$, e a variação no pH das matrizes, antes e após os processos de estabilização.

A CTCef apresentou uma tendência de aumento após os processos de compostagem e maior ainda após a vermicompostagem. Isso sugere que os coloides orgânicos do vermicomposto têm uma maior habilidade em adsorver cátions na solução do solo do que os compostos, podendo depois cedê-los ou efetuar trocas, caso ocorra uma concentração de íons diferente ou uma variação de $\mathrm{pH}$.

Analisando a Tabela 1 nota-se uma ligeira tendência na diminuição do valor do $\mathrm{pH}$ refletindo em um aumento na acidez das amostras, logo uma diminuição da basicidade das matrizes. Estudos atribuem a diminuição do valor do $\mathrm{pH}$ à produção de $\mathrm{CO}_{2}$ e de ácidos orgânicos por atividade microbial presente durante os processos de compostagem e vermicompostagem, além disso, o processo de humificação gera radicais passíveis de serem desprotonados, como ácidos carboxílicos, que podem contribuir para a diminuição da basicidade das amostras. ${ }^{19}$

\section{Determinação do nitrogênio Kjeldahl total e do fósforo total}

A Figura 2 apresenta a variação dos parâmetros NKT e $\mathrm{P}_{\text {total }}$ antes e após os processos de compostagem e vermicompostagem.

Tabela 1. Valor da soma dos cátions metálicos totais (S), acidez trocável (AT), CTCef e pH das matrizes iniciais, dos compostos e dos vermicompostos (resultados expressos em $\mathrm{cmol}_{\mathrm{c}} \mathrm{kg}^{-1}$ )

\begin{tabular}{cccccccccc}
\hline Amostra & $\mathrm{S}$ & $\mathrm{e}$ & $\mathrm{AT}$ & $\mathrm{e}$ & $\mathrm{CTCef}$ & $\mathrm{e}$ & $\mathrm{pH}$ & $\mathrm{e}$ \\
\hline PAI & 29,92 & 0,26 & 0,52 & 0,08 & 30,44 & 0,34 & 8,93 & 0,04 \\
PAC & 30,80 & 0,64 & 0,42 & 0,08 & 31,22 & 0,72 & 8,49 & 0,04 \\
PAV & 32,16 & 0,57 & 0,22 & 0,08 & 32,38 & 0,65 & 8,29 & 0,01 \\
BCI & 23,53 & 0,79 & 0,38 & 0,08 & 24,56 & 0,87 & 7,73 & 0,07 \\
BCC & 27,75 & 0,19 & 0,24 & 0,05 & 27,99 & 0,24 & 7,58 & 0,01 \\
BCV & 29,55 & 0,74 & 0,21 & 0,02 & 29,76 & 0,47 & 7,13 & 0,06 \\
RVI & 32,65 & 0,40 & 0,46 & 0,07 & 33,11 & 0,46 & 8,97 & 0,02 \\
RVC & 34,06 & 0,42 & 0,42 & 0,06 & 34,48 & 0,48 & 8,74 & 0,02 \\
RVV & 35,55 & 0,25 & 0,11 & 0,00 & 35,66 & 0,25 & 8,55 & 0,03 \\
\hline
\end{tabular}

$\mathrm{PAI}=$ palha de arroz + esterco bovino inicial; $\mathrm{PAC}=$ palha de arroz + esterco bovino compostados; $\mathrm{PAV}=$ palha de arroz + esterco bovino vermicompostados; $\mathrm{BCI}=$ bagaço de cana + esterco bovino inicial $; \mathrm{BCC}=$ bagaço de cana + esterco bovino compostado; $\mathrm{BCV}$ = bagaço de cana + esterco bovino vermicompostados; $\mathrm{RVI}=$ resíduo vegetal + esterco bovino inicial $; \mathrm{RVC}$ = resíduo vegetal + esterco bovino compostados; RVV = resíduo vegetal + esterco bovino vermicompostados; e $=$ erro para um intervalo de confiança de $95 \%$ e para $\mathrm{n}=25$, onde $\mathrm{n}=$ número de amostras. 

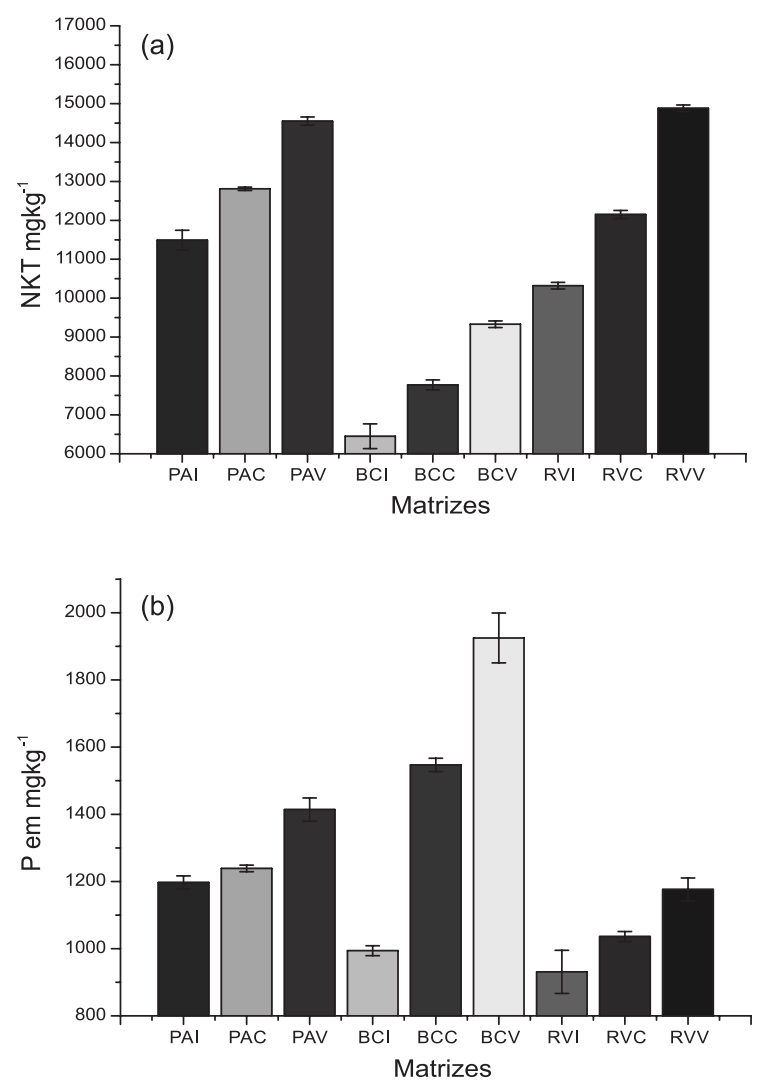

Figura 2. (a) Nitrogênio Kjeldahl total (NKT) e (b) quantidade de fósforo total $(P)$ das matrizes estudadas: PAI (palha de arroz + esterco bovino inicial), PAC (palha de arroz + esterco bovino compostados), PAV (palha de arroz + esterco bovino vermicompostados); BCI (bagaço de cana + esterco bovino inicial), BCC (bagaço de cana + esterco bovino compostados), BCV (bagaço de cana + esterco bovino vermicompostados); RVI (resíduo vegetal + esterco bovino inicial), RVC (resíduo vegetal + esterco bovino compostados), RVV (resíduo vegetal + esterco bovino vermicompostados)

Analisando a Figura 2 observa-se que as quantidades de NKT e de $\mathrm{P}_{\text {total }}$ aumentaram durante o processo de compostagem e, mais ainda, durante a vermicompostagem. $\mathrm{O}$ aumento de NKT e de $\mathrm{P}_{\text {total }}$ intensifica a capacidade fertilizante do vermicomposto final, uma vez que o nitrogênio e o fósforo são dois nutrientes essenciais para o crescimento e desenvolvimento das plantas.

Segundo Atiyeh e colaboradores, ${ }^{20} \mathrm{o}$ aumento de nutrientes minerais, tais como nitrogênio e fósforo, está diretamente relacionado com a mineralização da matéria orgânica pelas minhocas. Uma vez que existe a evolução de $\mathrm{CO}_{2}$ para o meio, há uma "concentração" dos nutrientes minerais no produto final, como a vermicompostagem acaba por promover uma diminuição maior no teor de matéria orgânica, esta também apresenta uma maior concentração nos nutrientes nitrogênio e fósforo do que o processo de compostagem, sugerindo que o processo de vermicompostagem se apresenta como uma ferramenta mais eficiente em um curto intervalo de tempo.

\section{Razão C/N e razão CTCef/COT}

A razão C/N bem como a CTCef/COT são indicativos do grau de maturação dos vermicompostos, sendo aplicadas aos fertilizantes orgânicos mistos, aos compostos e aos vermicompostos. Os valores para a variação da razão C/N e da CTCef/COT ao início e ao fim dos processos de compostagem e de vermicompostagem estão apresentados na Tabela 2.

A determinação da relação $\mathrm{C} / \mathrm{N}$ é considerada um dos métodos
Tabela 2. Variação da razão C/N e CTCef/COT $\left(\mathrm{cmol}_{\mathrm{c}} \mathrm{kg}^{-1}\right)$ no início e ao final dos processos de compostagem e de vermicompostagem

\begin{tabular}{ccccc}
\hline Amostra & C/N & e & CTCef/COT & e \\
\hline PAI & 41,06 & 5,59 & 75,9 & 5,00 \\
PAC & 30,86 & 2,14 & 92,7 & 3,70 \\
PAV & 25,55 & 1,37 & 101,8 & 1,60 \\
BCI & 55,62 & 9,19 & 79,5 & 2,80 \\
BCC & 42,30 & 4,05 & 100,1 & 2,20 \\
BCV & 33,55 & 2,10 & 111,2 & 1,90 \\
RVI & 35,92 & 2,00 & 104,5 & 2,30 \\
RVC & 27,55 & 1,00 & 120,2 & 1,20 \\
RVV & 20,81 & 1,60 & 135,2 & 2,70 \\
\hline
\end{tabular}

$\mathrm{PAI}=$ palha de arroz + esterco bovino inicial $; \mathrm{PAC}=$ palha de arroz + esterco bovino compostados; PAV = palha de arroz + esterco bovino vermicompostados; $\mathrm{BCI}=$ bagaço de cana + esterco bovino inicial; $\mathrm{BCC}=$ bagaço de cana + esterco bovino compostado; $\mathrm{BCV}=$ bagaço de cana + esterco bovino vermicompostados; $\mathrm{RVI}=$ resíduo vegetal + esterco bovino inicial; $\mathrm{RVC}=$ resíduo vegetal + esterco bovino compostados; RVV = resíduo vegetal + esterco bovino vermicompostados; $\mathrm{e}=$ erro para um intervalo de confiança de $95 \%$ e para $\mathrm{n}=25$, onde $\mathrm{n}=$ número de amostras.

mais simples para se avaliar a capacidade de assimilação do nitrogênio pelas plantas em um resíduo orgânico. ${ }^{21} \mathrm{~A}$ relação $\mathrm{C} / \mathrm{N}$ do húmus estabilizado, pronto para ser utilizado nas culturas, deve estar entre 15 e $20 .{ }^{22} \mathrm{O}$ produto final com valores de $\mathrm{C} / \mathrm{N}$ superiores a 20 pode causar impactos negativos para as plantas. ${ }^{23}$

Os valores para a razão $\mathrm{C} / \mathrm{N}$ apresentaram um decréscimo ao longo dos processos de compostagem e de vermicompostagem, sendo esta diminuição mais acentuada nas matrizes vermicompostadas. Isto ocorre devido à diminuição que se observou na percentagem de COT e ao aumento na quantidade de NKT. A aceleração no processo de humificação promovido pelas minhocas durante a vermicompostagem promove uma diminuição na razão $\mathrm{C} / \mathrm{N},{ }^{20}$ no entanto, de todos os produtos obtidos apenas o RVV apresentou uma razão $\mathrm{C} / \mathrm{N}$ próxima à indicada, esse parâmetro talvez possa ser melhorado aumentando-se o tempo de compostagem ou vermicompostagem para as demais matrizes.

A normatização da CTCef pelo teor de COT fornece um indicativo melhor da capacidade de troca catiônica das matrizes e do processo de estabilização desses materiais, pois considera os diferentes teores de $\mathrm{C}$ nos resíduos e as perdas durante a vermicompostagem.

A vantagem da utilização da CTCef é que, além de qualificar o material orgânico, esse índice traz uma informação muito significativa do ponto de vista agronômico, ou seja, a melhoria de retenção de nutrientes que esses produtos podem proporcionar ao serem incorporados ao solo. ${ }^{24} \mathrm{~A}$ relação CTCef/COT é um indicativo do grau de maturação e qualidade dos fertilizantes orgânicos, sendo mais apropriada que a relação $\mathrm{C} / \mathrm{N}$ para indicar o grau de humificação de materiais orgânicos, pois esta última pode ser afetada seriamente pela presença de nitrogênio amoniacal, como ocorre no esterco de galinha.

Quanto à relação CTCef/COT foi observado um aumento após os processos estudados, como observado na Tabela 2. Em todos os experimentos pode-se observar que o processo de vermicompostagem apresenta valores para a relação CTCef/COT maiores do que os obtidos para os processos de compostagem, indicando que o processo de vermicompostagem é mais eficiente para a estabilização dos resíduos estudados (quando comparado com o processo de compostagem), uma vez que a CTCef/COT reflete o índice de maturação das matrizes estudadas. 
Espectros de infravermelho e determinação da razão $E_{4} / E_{6}$ por meio de espectroscopia na região do UV/Vis

A Figura 3 apresenta os espectros no infravermelho (modo transmitância) e UV/Vis das matrizes iniciais, compostadas e vermicompostadas durante 3 meses.

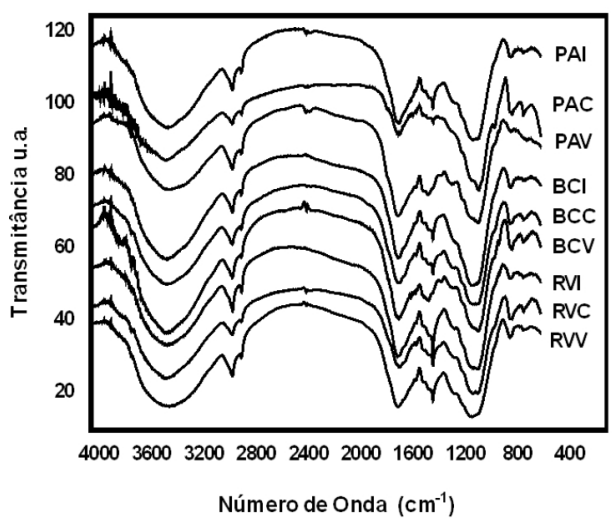

Figura 3. Espectros de infravermelho das matrizes estudadas. PAI (palha de arroz + esterco bovino inicial), PAC (palha de arroz + esterco bovino compostados), PAV (palha de arroz + esterco bovino vermicompostados); BCI (bagaço de cana + esterco bovino inicial), BCC (bagaço de cana + esterco bovino compostados), BCV (bagaço de cana + esterco bovino vermicompostados); RVI (resíduo vegetal + esterco bovino inicial), $R V C$ (resíduo vegetal + esterco bovino compostados), RVV (resíduo vegetal + esterco bovino vermicompostados)

Analisando a Figura 3 observa-se a semelhança que possuem as três matrizes (PA, BC e RV) iniciais e após os processos de compostagem e vermicompostagem, nota-se que os espectros de infravermelho são muito semelhantes apresentando bandas largas, que dificultam a caracterização das matrizes, devido às sobreposições.

Todos os espectros apresentam basicamente as mesmas bandas, uma larga em $3400 \mathrm{~cm}^{-1}$ devido ao estiramento de $\mathrm{O}-\mathrm{H}$, uma banda próxima de $2940 \mathrm{~cm}^{-1}$ relativa ao estiramento simétrico e assimétrico de C-H alifático, uma banda próxima a $1630 \mathrm{~cm}^{-1}$ referente ao estiramento de $\mathrm{C}=\mathrm{C}$ aromático, uma banda relativamente alargada próxima a $1400 \mathrm{~cm}^{-1}$ associada ao estiramento de C-O fenólico, deformação de O-H carboxílico, deformação de C-H alifático e estiramento assimétrico de $\mathrm{C}=\mathrm{O}$ de carboxilatos, uma banda alargada próxima a 1170 $\mathrm{cm}^{-1}$ relativa ao estiramento de $\mathrm{C}-\mathrm{O}$ de estruturas polissacarídicas e estiramento de Si-O.

A relação entre as absorbâncias de determinadas bandas tem sido utilizada por alguns autores. ${ }^{25}$ Dessa forma, a relação entre as absorbâncias em 2927 e em 1050 cm$^{-1}$ (relação entre grupos apolares e polares) fornece o índice de hidrofobicidade (quanto maior esse índice, maior resistência à degradação microbiana). A relação entre as absorbâncias em 1660 e em 2929 cm$^{-1}$ corresponde ao índice de aromaticidade.

A Tabela 3 apresenta os índices de hidrofobicidade $(\mathrm{H})$, o índice de aromaticidade (A) e a razão $\mathrm{E}_{4} / \mathrm{E}_{6}$, esta última obtida a partir dos espectros de UV/Vis.

A Tabela 3 mostra que os vermicompostos possuem os maiores índices de hidrofobicidade, sendo assim, possuem uma maior resistência à degradação microbiana, isso sugere que matrizes vermicompostadas possuem um maior grau de humificação, quando comparadas às matrizes iniciais e às matrizes compostadas.

Já o índice de aromaticidade é menor nos vermicompostos, indicando que nestas matrizes houve uma maior degradação dos grupamentos aromáticos. Isso será esclarecido após o fracionamento e
Tabela 3. Índice de hidrofobicidade (H), índice de aromaticidade (A) e razão E4/E6 para os compostos e vermicompostos avaliados

\begin{tabular}{ccccccc}
\hline Amostra & $\mathrm{H}$ & $\mathrm{e}$ & $\mathrm{A}$ & $\mathrm{e}$ & $\mathrm{E}_{4} / \mathrm{E}_{6}$ & $\mathrm{e}$ \\
\hline PAI & 1,19 & 0,02 & 0,89 & 0,00 & 3,64 & 0,12 \\
PAC & 1,35 & 0,05 & 0,81 & 0,02 & 3,49 & 0,11 \\
PAV & 1,55 & 0,00 & 0,72 & 0,03 & 3,34 & 0,11 \\
BCI & 1,24 & 0,03 & 0,96 & 0,02 & 3,63 & 0,15 \\
BCC & 1,34 & 0,04 & 0,83 & 0,03 & 3,51 & 0,11 \\
BCV & 1,82 & 0,02 & 0,76 & 0,00 & 3,36 & 0,13 \\
RVI & 1,10 & 0,03 & 0,84 & 0,02 & 3,46 & 0,14 \\
RVC & 1,11 & 0,02 & 0,81 & 0,03 & 3,44 & 0,13 \\
RVV & 1,22 & 0,00 & 0,66 & 0,01 & 3,18 & 0,12 \\
\hline
\end{tabular}

$\mathrm{PAI}=$ palha de arroz + esterco bovino inicial $; \mathrm{PAC}=$ palha de arroz + esterco bovino compostados; PAV = palha de arroz + esterco bovino vermicompostados; $\mathrm{BCI}=$ bagaço de cana + esterco bovino inicial; $\mathrm{BCC}=$ bagaço de cana + esterco bovino compostado; $\mathrm{BCV}=$ bagaço de cana + esterco bovino vermicompostados; $\mathrm{RVI}=$ resíduo vegetal + esterco bovino inicial $; \mathrm{RVC}=$ resíduo vegetal + esterco bovino compostados; RVV = resíduo vegetal + esterco bovino vermicompostados; e = erro para um intervalo de confiança de $95 \%$ e para $\mathrm{n}=25$, onde $\mathrm{n}=$ número de amostras.

caracterização das substâncias húmicas, das matrizes aqui estudadas.

Os dados experimentais obtidos podem ser justificados pelos diferentes métodos de degradação promovidos pelos dois processos: vermicompostagem e compostagem. Durante o processo de degradação, as moléculas orgânicas com maior número de grupamentos polares são mais facilmente degradáveis quando comparadas com moléculas orgânicas apolares, sendo assim, materiais com alto grau de estabilização tendem a apresentar maior quantidade de substâncias apolares em sua constituição química. Isso significa que a parcela de material mais lábil já foi consumida, logo, um maior índice de hidrofobicidade indica que o material em questão se encontra mais "estabilizado" do que as matrizes iniciais e compostadas, o inverso se observa para o indicie de aromaticidade. Vale ressaltar que tais índices só trazem alguma informação se comparados entre as mesmas matrizes variando apenas o tempo de análise e os processos de estabilização; matrizes diferentes apresentam constituições químicas diferentes, o que acaba por impossibilitar uma comparação efetiva.

Em relação à razão $E_{4} / E_{6}$, as amostras de vermicomposto apresentaram valores consideravelmente menores. Como o parâmetro $E_{4} / E_{6}$ diminui com o grau de humificação, esses resultados são um primeiro indicativo do maior grau de humificação do vermicomposto. ${ }^{26}$

Todos os diferentes parâmetros de caracterização utilizados estão correlacionados em maior ou menor grau, pois refletem basicamente o mesmo processo de reações de estabilização de compostos orgânicos. De todos os resultados obtidos pode-se afirmar que a vermicompostagem, para os resíduos estudados e para o procedimento experimental utilizado, proporciona um produto mais estabilizado, em curto intervalo de tempo, sendo dessa forma mais eficiente na estabilização de compostos orgânicos, quando comparada com a compostagem.

\section{CONCLUSÕES}

Analisando as matrizes iniciais, os compostos e os vermicompostos produzidos, verificamos que as características físico-químicas das matrizes após passarem pelos processos de compostagem e vermicompostagem sofreram alterações, elevando o grau de humificação de todas as matrizes iniciais, havendo um aumento na CTCef, no NKT no $\mathrm{P}_{\text {total }}$, uma diminuição na razão $\mathrm{C} / \mathrm{N}$, um aumento na razão CTCef/COT. 
Levando-se em consideração o fato de uma excelente adaptação das minhocas às matrizes, o processo de vermicompostagem mostra-se ideal para ser utilizado na estabilização dos resíduos estudados, pois ao fim do processo, além de obter-se um fertilizante orgânico com um alto grau de estabilização, têm-se também outro produto que pode ser comercializado: as minhocas.

De maneira geral, os resultados obtidos mostram que o processo de vermicompostagem é mais eficaz na estabilização dos resíduos orgânicos aqui estudados, quando comparado com o processo de compostagem.

\section{AGRADECIMENTOS} financeiro.

Ao CNPq e à FAPESP, processo número 07/50776-4, pelo apoio

\section{REFERÊNCIAS}

1. Beigl, P.; Lebersorger, S.; Salhofer, S.; Waste Manage. 2008, 28, 200.

2. Gil, M. V.; Carballo, M. T.; Calvo, L. F.; Waste Manage. 2008, $28,1432$.

3. Landgraf, M. D.; Messias, R. A.; Rezende, M. O. O.; A importância ambiental da vermicompostagem: vantagens e aplicações, $1^{\text {a }}$ ed., Rima: São Carlos, 2005.

4. Kiehl, E. J.; Manual de compostagem: maturação e qualidade do composto, $4^{\mathrm{a}}$ ed., DeGaspari: Piracicaba 2004.

5. Sharma, S.; Pradhan, K.; Satya, S.; Vasudevan, P.; JACS 2005, 1, 4.

6. Yadavand, A.; Garg, V.; J. Hazard. Mater. 2009, 168, 262.

7. Edwards, C. A.; Fletcher, K. E.; Agr. Ecosyst. Environ. 1988, 24, 235.

8. Aquino, A. M.; Almeida, D. L.; Silva, V. F.; Comunicado Técnico, 8, Centro Nacional de Pesquisa Biológica do Solo: Rio de Janeiro, 1992.
9. Budziak, C. R.; Maia, C. M. B. F.; Mangrich, A. S.; Quim. Nova 2004, $27,399$.

10. Garg, P.; Gupta, A.; Satya, S.; Bioresour. Technol. 2006, 97, 391.

11. Landgraf, M. D.; Rezende, M. O. O.; Ciência e Cultura 1997, 49, 117.

12. Landgraf, M. D.; Alves, M. R.; Silva, S. C.; Rezende, M. O. O.; Quim. Nova 1999, 22, 483

13. Grigatti, M.; Ciavatta, C.; Gessa, C.; Bioresour. Technol. 2004, 91,163.

14. Embrapa; Manual de Métodos de Análise do Solo, Sociedade Brasileira de Ciência do Solo; Rio de Janeiro, 1979.

15. Prado, A. G. S.; Souza, S. M.; Silva, W. T. L.; Rezende, M. O. O.; Quim. Nova 1999, 22, 896.

16. Abreu Jr., C. H.; Muraoka, T.; Oliveira, F. C.; Sci. Agric. 2001, 58, 813.

17. Claessen, M. E. C., org.; Manual de métodos de análise do solo, $2^{\mathrm{a}} \mathrm{ed}$.; EMBRAPA-CNPS: Rio de Janeiro, 1997.

18. Cotta, J. A. O.; Salami, F. H.; Marques, A. R.; Rezende, M. O. O.; Landgraf, M. D.; Revista Analytica 2007, 26, 68.

19. Albanell, E.; Plaizats, J.; Cabrero, T.; Biol. Fert. Soils 1988, 6, 266.

20. Atiyeh, R. M.; Edwards, C. A.; Subler, S.; Metzger, J. D.; Bioresour. Technol. 2001, 78, 11 .

21. Lopez, M. J.; Elorrieta, M. A.; Vaargas-Garcia, M. C.; Suarez-Estrella, F.; Moreno, J. T.; Bioresour. Technol. 2002, 81, 123.

22. Kayhanian, M.; Tchobanoglous, G.; J. Sci .Technol. 1993, 27, 133.

23. Pullicino, D. S.; Dissertação de Mestrado, Department of Chemistry, University of Malta, 2002.

24. Rodella, A. A.; Alcarde, J. C.; Sci. Agric. 1994, 51, 556.

25. Freixo, A. A.; Canellas, L. P.; Machado, F.; Rev. Bras. Ci. Solo 2002, 26, 445.

26. Kononova, M. M.; Soil Organic Matter, its Nature, its Role in Soil Formation and in Soil Fertility, $2^{\text {nd }}$ ed., Pergamon: New York, 1996. 